\title{
El corazón de la espiritualidad jesuita y la misión profética en favor de los pobres. Una meditación bíblica*
}

\author{
Aloysius Pieris, S.J., \\ Tulana Research Centre, \\ Gonawaia-Kelaniya, \\ Sri Lanka.
}

\section{El trasfondo histórico. Una reflexión sobre la tradición}

"El corazón" de la espiritualidad de la Compañía de Jesús es el "corazón de Jesús". Hacia finales del siglo XVII, la espiritualidad jesu-céntrica comenzó a configurarse como "devoción al Sagrado Corazón de Jesús", tendencia que comenzó con las "revelaciones" del Sagrado Corazón. Estas fueron entregadas -así se creyó- a través de María Alacoque a su confesor jesuita Claudio de la Colombière, y, a través de él, a toda la Compañía de Jesús. Más tarde, la encíclica Haurietis Aquas le concedió tal importancia que se impuso en toda la Iglesia, no sólo entre los jesuitas, como una importante dimensión de la espiritualidad cristiana.

Uno de los elementos principales de esta devoción consistía en la consagración de individuos, familias y comunidades cristianas al Sagrado Corazón. Prácticas como la de los primeros viemes y otras tenían su fundamento en la creencia de que los devotos y devotas deblan hacer reparación por el daño que los pecadores infligían al corazón de Jesús. Se exhortaba, así, a hacer oración y aclos de penitencia como reparación y consolación al corazón sufriente de Jesús.

Las palabras "consagración", "consolación" y "reparación" reproducen, pues, la teología de una específica época de la historia, en la que se llegó a configurar esta devoción. Para que ésta pueda tener hoy algún significado hay

- Versión revisada de una charla a jesuitas de la asistencia de Asia del Sur, el 12 de noviembre de 2001, en Lewella, Kandy, Sri Lanka. 
que evaluar sus presupuestos teológicos, a la luz de la Biblia y de los desafíos apostólicos actuales, especialmente el desafío de los pobres.

Como paso previo, habrá que analizar el significado de la palabra "corazón", lo cual juzgamos de importancia decisiva, pues, aunque pueda parecer duro el decirlo, en ello se decide si en la devoción al corazón de Jesús se trata de una devoción o de una desviación. Y decimos esto porque la imagen que tenemos del corazón fisiológico llegó a ser - y sigue siendo- un elemento indispensable de esta práctica devocional.

Antes de comenzar el análisis, debo confesar que me ha hecho pensar seriamente la opinión de algunos artistas cristianos contemporáneos, según los cuales, recurrir al simbolismo del corazón es algo tan incongruente como lo sería usar una pintura del cerebro humano para simbolizar, por ejemplo, la inteligencia de Aristóteles.

Esta crílica es importante y plantea dos preguntas relacionadas entre sí: a) cuál es el símbolo adecuado para expresar el amor entre Jesús y nosotros, y b) cuál es el significado real del corazón, en la espiritualidad cristiana.

\subsection{El símbolo adecuado}

Como lo han hecho notar los estudiosos del arte, durante e inmediatamente después de la época renacentisla (es decir, la época en que vivió Claudio de la Colombière), los grandes maestros solían hacer uso de dos formas artísticas distintas para expresar de manera pictórica el amor de Dios, encamado en Jesús. Una es el rostro humano de Jesús, que irradiaba la "locura de la cruz", es decir, el "amor loco, apasionado", que es lo que Dios quería mostramos. La otra sería, en forma pictórica más serena, mostrar a Jesús en el acto mismo de manifestar ese amor, es decir, en el acto de dar de comer al hambriento o de sanar al enfermo; de predicar la buena noticia a los pobres o de orar por sus débiles compañeros de trabajo; de tocar a los intocables o de acariciar a los pequeños; de confortar a los afligidos o de devolver dignidad a las mujeres; de perdonar a los pecadores o de comer con los marginados; y sobre todo, en el acto final de su inmolación en la cruz. Según esto, el símbolo de amor más elocuente es la acción. Dicho lo mismo en palabras de san Ignacio, "el amor se debe mostrar en hechos más que en palabras" (Ejercicios Espirituales, n. 230).

$\mathrm{Y}$ ahora nos preguntamos, ¿es el órgano fisiológico del corazón humano la expresión adecuada de este mensaje dinámico? ¿No es un signo devocional más que un signo que mueve a la acción? Desde un punto de vista histórico, los artistas del renacimiento, quienes con su humanismo influyeron en "la cultura" de los jesuitas -incluso en la época en que Claudio de la Colombière promovió, en la Compañía de Jesús, la devoción al Sagrado Corazón-, no pudieron haber pensado en pintar un "corazón humano" para simbolizar el corazón de Cristo. El símbolo o sacramento elegido por el mismo Dios para expresar el 
amor de su propio Hijo fue el hombre Jesús en acción - y nada se puede hacer para mejorar esa decisión de Dios. Este es el primer axioma para comenzar la reflexión sobre "el corazón de la espiritualidad jesuita".

Para no inquietar a quienes están acostumbrados a asociar demasiado estrechamente la pintura del corazón físico con el amor de Dios, manifestado en Jesús, quisiera citar desde el comienzo la advertencia que, ya en los primeros siglos de la Iglesia, hizo el Sexlo Concilio Ecuménico (Trullanum 692). Como observa Leonid Ouspensky, en ese Concilio, la Iglesia definió por primera vez el carácter y significado fundamental de las imágenes sagradas. Ya habían amainado las controversias sobre la divinidad y la humanidad de Cristo, y los "símbolos" comenzaron a ser usados con más frecuencia que la propia imagen humana de Jesús. Esto es lo que proclama el concilio en el canon 82:

Decretamos, por lo tanto, que Cristo nuestro Dios, el Cordero que quitó el pecado del mundo, sea representado en su forma humana, y no en la forma de un vetusto cordero, para que se comprenda la humillación de Dios - la Palabra-, para que sea recordada su vida en la came, así como su pasión y su muerte salvífica, y así también la redención del mundo. (Cursivas del autor).

En otras palabras, los acontecimientos de su "vida en la carne", especialmente su "humillación", su "pasión y muerte salvíficas" son los rasgos de la humanidad de Jesús, que simbolizan su amor. Pero si esto es así, el corazón humano físico — que apareció tardiamente, en la historia del arte sagrado— no hace justicia a lo que debe ser expresado, es decir, la realidad y significado de la humanidad de Crislo. En esto, la enseñanza del sexto concilio ecuménico es una guía segura. La humanidad de Cristo permanecerá siempre como el último sacramento del amor de Dios, el símbolo más inspirador, que nos lleva a la acción.

Esta es la razón que me ha llevado a hacer una distinción entre el uso simbólico del corazón fisico para comunicar el amor de Cristo (lo que ahora estamos analizando) y el significado de la palabra "corazón", en la espiritualidad tradicional de la Iglesia, que analizaremos a continuación.

Según el ex-jesuita Henri Bremont (1885-1933), una autoridad en la historia de la espiritualidad francesa, el culto de san Juan Eudes al Sagrado Corazón suponía una espiritualidad leocéntrica alrededor del "corazón" como símbolo de lo interior de Cristo, mientras que en la versión que comenzó con las visiones de Margarita María Alacoque, es decir, en la devoción que propició la Compañía de Jesús, el órgano físico del corazón quebrado se convirtió en una poderosa imagen del amor de Cristo. La presentación iconográfica de Cristo con su corazón fisiológico atravesado y sangrante fue un desarrollo lógico de esta nueva devoción.

Pero aquí surge la pregunta de si este cambio se debió meramente a la imaginación católica. francesa. Gordon Wakefield afirma que incluso puritanos 
ingleses, como Isaac Ambrose, Richard Baxter y Thomas Godwin, ya habían recurrido, en sus himnos y tratados, a ese mismo lenguaje vigoroso del corazón traspasado de Cristo. El problema no está, pues, en el estilo literario, usado tanto por católicos como por protestantes, sino en su versión pictórica. Clarifiquemos este punto, analizando el estilo literario

\subsection{El significado de "corazón"}

El corazón de Cristo ya era mencionado en los escritos espirituales de la edad media, más de medio milenio antes de que apareciese la versión jesuita. Lo encontramos en la Vita Mystica y, en general, en los escritos de san Buenaventura, san Anselmo, san Bernardo, santa Mechlild y santa Gertrudis. Esta referencia al corazón en el discurso espiritual constituye siempre un vigoroso estilo literario, pero no evoca necesariamente la imagen pictórica del corazón físico. Y para ello hay una razón bien sencilla. Como ha observado Rahner, corazón es una "palabra primordial", que significa lo más íntimo y central de la propia personalidad, $y$, en ese sentido, no difiere de otras expresiones como el "costado de Cristo" (latus Christi) o las "entrañas de misericordia" (viscera misericordiae), etc., que aparecen recurrentemente en la Biblia y en los Padres.

Así mismo la raíz sánscrita $h r d$ (que filológicamente está relacionada con la palabra inglesa "corazón") es comprendida en la literatura budista temprana como la sede de nuestra consciencia (cit). Las acciones que expresan y caracterizan quiénes somos, brotan del lugar más íntimo de la consciencia. También la raíz shrd (otra versión de $h r d$ ), de la cual proviene shraddha (fe), es la versión palatial de la raíz gutural indoeuropea de la que se derivan tanto el griego cardia (corazón) como el latín credo (yo creo, yo tengo fe). El parentesco etimológico entre shraddha (fe) y hrd (corazón) en sánscrito, así como el parentesco entre credo (yo creo) y cardia (corazón), remite a la raiz misma del lenguaje humano. No es de extrañar, pues, que entre lo que creo en mi corazón (mi fe) y lo que expreso en acciones existe una intrínseca reciprocidad.

Volviendo a la historia de la espiritualidad cristiana, los grandes santos siempre han forcejeado por nombrar este centro íntimo de nuestro ser o la sede de nuestra conciencia, allí donde ocurre lo que define la propia personalidad. Santa Teresa de Avila en Las Moradas se refiere a ello como el "centro del alma", que, literalmente, fue una apropiación cristiana del kentron psyches del que Plotino habla en su Enneada. Muchos místicos medievales usaron palabras como synderesis (¿conciencia?) o apex mentis seu scintilla animae (el culmen de la mente o la chispa del alma), tal como lo hace, por ejemplo, Buenaventura, en su Itinerarium. Se Irata aquí de una realidad espirilual que no puede ser fácilmente expresada en forma pictórica, porque no puede ser localizada fisiológicamente. El corazón físico es incapaz de evocar de modo adecuado este significado. 
Lo que con esto queremos enfatizar es que la palabra "corazón" (el idioma literario, no la expresión pictórica) es la forma más común de referimos a esta realidad inexpresable. Es aquello en que somos verdaderamente nosotros mismos. Es aquello en que descubrimos y descodificamos el secreto nombre con el que Dios llama a la existencia a cada uno de nosotros. Es aquello en que encontramos la palabra creativa con la que Dios se dirige a mi en lo personal. Es aquello en que reconocemos, por nombre, quién desea Dios que sea, el nombre que contiene mi misión específica, tal como Dios la quiere. Más aún, diría que todo crecimiento espiritual va necesariamente acompañado del descubrimiento progresivo de este código secreto de identidad que, desde la concepción, llevamos en nuestro "corazón", y de la respuesta, cada vez mayor, que damos a ello. De ahí que todo lo que sucede en ese secreto lugar, bueno o malo, deja una huella visible en nuestra personalidad. Ahí, en el corazón, es donde debemos buscar conversión y progreso espiritual. Y de ahí que la petición bíblica sea la circuncisión del corazón, más que la de la carne.

Apliquemos ahora a Cristo esta noción de "corazón". Cuando hablamos del "corazón de Cristo", estamos hablando de aquello que le hace Cristo, es decir, el amor de Dios, que desemboca en acción desde el centro mismo de su ser. Pues esto es lo que la "Palabra de Dios" - dabar Yahweh- significa en la Biblia cuando es aplicada a Jesús: una palabra-acción o un hecho hablado. Eso es lo que realmente es Jesús. En él, hablar de Dios coincide con la acción de Dios. El es la palabra-acción en forma humana. En otras palabras, Cristo es la proclamación del amor de Dios, puesto en escena en una vida humana. La palabra de revelación es un gesto de amor

Si éste es el caso, el encuentro de nuestro corazón con el corazón de Jesús no es un ejercicio meramente devocional de una romántica contemplación del corazón, sino una fe programática que lleva al compromiso de hechos vigorosos de amor en favor de sus hermanos y hermanas más pequeños. Este es el compromiso que Jesús describe como "yugo suave" y "carga ligera", el cual él pone sobre nuestros hombros, como lo vamos a ver en la siguiente meditación de un texto bíblico, que nos lleva directamente al corazón de Cristo.

2. Jesús, "manso y humilde de corazón”. Meditación bíblica sobre Mateo 11,29

Olvidemos, pues, la imagen del corazón físico, pongámonos ante el hombre Jesús, y escuchémosle pronunciar su conocida sentencia:

Vengan a mí los que van cansados, llevando pesadas cargas, y yo los aliviaré. Carguen con mi yugo y aprendan de mí, que soy manso y humilde de corazón, y sus almas encontrarán descanso, pues mi yugo es suave y mi carga liviana (Mt 11, 29 -30). 
Este no ha sido el texto biblico clave en la devoción al Sagrado Corazón, sino que la inspiración bíblica fundamental provenía de la referencia joánica al costado traspasado de Cristo crucificado, del cual se dice que fluyó sangre y agua $(J n$ 19, 34). La encíclica que avala la devoción al corazón de Jesús comienza con las palabras Haurietis aquas ("saquen agua"), que hace alusion a Juan 19,34 , tomado conjuntamente con Juan 7, 37-40, donde el agua que fluye de su ser más íntimo ("entrañas", koilias) es identificada con el Espíritu.

Hoy, sin embargo, bien haremos en remitimos a Mateo 11, 29. Es el único pasaje en el cual Jesús usa la palabra "corazón", refiriéndose a sí mismo, revelándonos algo de su ser interior e invitándonos a participar en su yugo y en su carga - un yugo y una carga que están asociados a nuestro propio llegar a ser mansos y humildes de corazón como él.

Es cierto que las palabras mansedumbre y humildad pueden ser con fácilidad mal interpretadas y pueden producir una imagen distorsionada de Jesús, la persona a quienes somos llamados a imitar. En ese caso, bien pudiera ocurrir que, precisamente, cuando practicamos la devoción a su corazón, no estamos siguiendo al Jesús de los evangelios. Las palabras "manso y humilde", en efecto, tienen una resonancia específica en el Nuevo Testamento. En labios de Jesús aparecen sólo en Mateo, lo cual se puede deber con probabilidad al énfasis de éste en los microi (los pequeños de Dios). Como en otra frase mateana, "pobres en espiri$t u$ ", también aquí somos llamados a ser mansos y humildes de corazón, es decir, a serlo desde lo profundo de nuestro propio ser.

\subsection{Mansedumbre como ira profética y fuerza controlada en el servicio de Dios y los pequeños}

En el griego clásico, mansedumbre (praotes) es, según William Barclay, una "bella palabra", que significa dulzura, como cuando se habla de una dulce brisa. Para Aristóteles es una virtud, y por lo tanto, siempre está entre dos extremos. In medio stat virtus: "la virtud está en el medio", dice. De la mansedumbre se dice que está en medio de dos extremos; un extremo es orgilotes o ira incontrolable; el otro es aorgesia (incapacidad para encolerizarse en absoluto). Dicho en lenguaje común y corriente, el manso no es "ni una bestia", fácilmente provocable a ataques de rabia destructora, ni es un "vegetal", incapaz de manifestar siquiera algo que se parezca a una reacción airada.

¿La conclusión? Ser manso (praus) es estar lleno de ira, pero en la medida adecuada, por la razón adecuada y en el momento adecuado. Una vez que la palabra entra en el Nuevo Testamento con este significado, supongo que debe hacer referencia a la "ira profética", que no es sino la ira de Dios, que reacciona contra la injusticia.

Después de todo, san Pablo pide que "nos enojemos, pero sin pecar" (Ef 4, 26), porque, presumiblemente, aceptaba la legilimidad y la necesidad de una ira 
no pecaminosa. Ira no es odio. Ira muy bien pudiera ser una expresión de amor. Jesús controló su ira cuando él mismo fue traicionado y blasfemado, capturado y torturado, al final, asesinado, a sangre fría. Sin embargo, sí se dejó apoderar de una furia sagrada cuando en el templo Dios era cambiado por Mammon, y cuando los pequeños (los pobres y los pecadores) eran discriminados o dañados. Esta es la ira profética, ira al servicio de Dios y del pobre, pues Dios y el pobre son los compañeros de Alianza que defendian los profetas. Siempre que se peca contra alguno de ellos, Dios o el pobre, el profeta protesta vehementemente.

Así, en el libro de Números 12, 3, los redaclores posteriores llaman a Moisés “iel más manso de los humanos!", pues fue el primer "profeta" (también según los redactores posteriores). Esta asociación de mansedumbre y llamada profélica es comprensible. No es de extrañar, pues, que la tarea profética de "guiar en el juicio y enseñar los caminos de Dios" sea confiada a los mansos (Sal 25, 9). Cuando Jesús, cumpliendo la profecía de Zacarías 2, 2, entra en la ciudad de Jerusalén "manso y sentado sobre un asno" (Mi 21, 5), su primera acción fue limpiar el templo con santa ira.

Mansedumbre no es timidez. Es hacer que la cólera humana deje respirar la ira compasiva de Dios contra la injusticia, en defensa de sus víctimas. Esto es lo que Jesús fue, en lo profundo de su corazón.

Barclay señala tambiên un segundo significado, relacionado con el anterior, de la palabra prous, en griego, y mitis, en latín, que ilumina lo que hemos dicho antes. Connota el estado de quien ha controlado su propia fuerza bruta. En la literatura clásica, la palabra es usada normalmente en referencia, por ejemplo, a un caballo salvaje, que debe ser domado para que trabaje para su dueño, que debe ser entrenado para obedecer al freno y a la brida. Al hacerse manso, la fuerza bruta de la bestia no queda eliminada en absoluto, sino enjaezada para un noble propósito. Se hace disponible para el servicio. Detrás de la gentileza del manso, está la fuerza de acero, observa Barclay.

Suaves y gentiles, en verdad, son los fuertes, cuya fuerza está al servicio de quienes no son fuertes. Esta es la segunda característica de la mansedumbre y encaja con la primera, es decir, con el ejercicio de la ira profética, en favor de Dios y de los pequeños. El manso es suave con los pequeños, emplea su propia energía psicofísica en su favor, en lugar de usarla en beneficio propio. Con valentía, manifiesta su protesta airada contra quienes no son ni mansos ni pequeños. Este es un modus agendi típico del Jesús manso, que encontramos en los evangelios.

\subsection{Una parábola sobre la ira y la fuerza de los mansos}

Quizás podamos clarificar el doble significado de "mansedumbre" con una parábola. Para ello voy a recordar un cuento de niños de India. Lo leí en la 
versión Sinhala de Sydney Marcus. Quisiera volver a contar el cuento ahora, de tal manera que ilustre las dos características de mansedumbre, mencionadas más arriba, es decir, ira y fuerza disciplinada para el servicio. El cuento trata de un elefante llamado Mahagir, que significa "roca colosal" y que hace alusión a su fuerza gigantesca. Era una bestia salvaje y había sido domada y entrenada para servir a la gente como una trabajadora disciplinada.

Un día hubo una gran fiesta en el pueblo y los organizadores pensaron plantar una gran tienda para acomodar a lodos los habitantes, durante las actividades festivas. Para consinuirla había que poner un gran poste en medio del poblado. Los habitantes cavaron un gran hoyo, lo suficientemente amplio y profundo como para que cupiera el gran poste. Sólo Mahagir tenía fuerza suficiente para cargar con una carga tan grande y pesada, y para colocarla en el hoyo. Sus servicios eran indispensables. Al igual que en otras ocasiones, se presentó al lugar del trabajo, tal como lo había ordenado su dueño, en obediencia serena. Los habitantes del lugar, por su parte, estaban esperando para hacer su trabajo a que el elefante hubiese terminado el suyo.

Con toda facilidad, Mahagir cargó el poste, más grueso que su piema y muchas veces más largo que su cuerpo. A una orden de Mahout, Mahagir llevó el poste cerca del hoyo, mientras todos los pobladores contemplaban la escena con curiosa expectación. A la siguiente orden, el elefapte levantó el poste y lo mantuvo sobre el hoyo. Entonces llegó la orden final: "échalo al hoyo". Pero en ese momento, sucedió algo inesperado. El elefante se quedó quieto, sin moverse, con el poste en posición vertical, apoyándose sobre una de las orillas alrededor del hoyo.

El Mahout repitió la orden de poner el poste dentro del hoyo, pero Mahagir no obedeció. En todos los rostros apareció la sorpresa. El Mahout perdió el control y, dando chillidos, repitió la orden, hiriendo al elefante sin piedad con el láligo hasta que le abrió la piel. El elefante, sin embargo, permaneció tercamente quieto, como si estuviese pintado sobre tierra pintada.

El Mahout no era en absoluto un hombre manso. Dio rienda suella a su ira, usando el látigo con fuerza indiscriminada, hasla que las orejas del elefante sangraron tanto que también provocaron su ira. Era un hombre colérico. Mahagir, en cambio, demostró un gran autocontrol. Sin esfuerzo pudiera haber echado por tierra a Mahout. Lo pudiera haber golpeado con el poste, o lo pudiera haber destrozado, hasta darle muerte, bajo su inmenso pie. Sin embargo, no usaba su gran fuerza en forma destructora. Mahagir era, en verdad, un animal manso. Y, precisamente, debido a esa mansedumbre, mostraba también su ira para que todo el mundo la viera. Al son de la trompeta que se escuchaba en las colinas lejanas, hizo dar vueltas al poste y lo anojó con violencia a muchos metros de distancia, sobresaltando con su conducta desacostumbrada a quienes estaban mirando. 
Después ocurrió algo todavía más sorprendente. El inmenso poste de madera rebotó varias veces sobre la tierra hasta que se detuvo. Los pobladores vieron entonces que del agujero salió un gatito, y que comenzó a correr. Mahagir, en verdad, era un modelo de mansedumbre. Su fuerza gigantesca había sido muy bien disciplinada para servir a otros y no desplegaría esa fuerza para hacer daño, ni siquiera a la más pequeña de las criaturas, ni siquiera para vengarse de Mahoul, que lo perseguía descontrolado.

Mansedumbre no es cobardía ante la injusticia. Es más bien muestra de valentia en y a través de una acción, que dirige la atención de todos hacia la injusticia, provocando ast un rechazo absoluto. Esta fue la mansedumbre del corazón de Jesús.

\subsection{El corazón humilde de Jesús y los humildes de Jesús}

En el texto de Mateo, citado más arriba (Mt 11, 29), humildad está emparentada con mansedumbre (como también en Ef 4, 2 y Col 3, 1). Existe afinidad entre ambas. En griego la palabra "humilde" es tapeinos y su significado primero no está asociado a la virtud de la humildad como tal, sino a la condición social humilde del pobre, lo que los reduce al estado de siervos y esclavos, cuya vida, en consecuencia, queda subordinada al poder de los ricos. En el Antiguo Testameplo, la noción de mansedumbre se identificó tanto con esta clase de abyecta humildad que nunca se usó en referencia a Dios, como lo hace notar Schultz, en Kittel. El Nuevo Testamento, sin embargo, usa no sólo "mansedumbre", sino incluso "humildad", como característica del Hijo de Dios.

En Mateo 11, 29, humildad de corazón significa la humildad social interiorizada como obediencia humilde. Los humildes (tapeinoi) son los pobres que están humillados, debido a su status social. Dios siempre sella su alianza con estos humildes, nunca con los poderosos. Ahora bien, Jesús es la Alianza hecha carne y, por lo tanto, él es, a la vez, los dos socios de la Alianza, en uno; es, a la vez, Dios y humilde en uno.

De todo lo dicho se desprende que la humildad como condición social es esencial para comprender el corazón de Jesús. Así como el status social elevado (lgnacio lo llamaría riquezas, en los Ejercicios Espirituales, n. 142) lleva a la soberbia y de ahí a todos los otros pecados, así también el status social bajo ("pobreza" en los Ejercicios Espirituales n. 146) lleva a la humildad y de ahí a todo progreso espiritual. Por esa razón, he dicho antes que humildad (tapeinosis) es el status social bajo, tan internalizado (aceptado dentro del corazón) que genera humildad.

El Magnificat (Lc 1, 46-55) revela el papel de los humildes en la economia de la salvación. María se refiere a su propia tapeinasis o humildad apasionadamente. Cuando se alegra en Dios su salvador (vv. 46-47), da la razón para ello (v. 48): 
Porque la atención cariñosa de Dios recayó sobre el bajo słalus social de su joven-esclava (ésta es mi traducción de epeblepsen epi ten tapeinosin tes doules autou).

Nótese la sentida humildad con que María se refiere a sí misma: la nin̄aesclava de Dios (doules autou), la lípica actitud de los tapeinoi, como lo hemos visto más arriba. Aquí Dios "se fija con amor" (epeblepsen) o "es atraído a" algo en ella que hace las delicias de Dios. No es tanto la virtud de la humildad, sino la raíz de su humildad, es decir, su bajo status en la sociedad. La virginidad no era un símbolo de status en Israel (como sí lo era en la cultura grecorromana). Como dice Lucas 1, 26, la palabra de Dios

llegó (a una insignificante) ciudad llamada Nazareth en (la despreciada) Galilea a una virgen (es decir, a una mujer todavia improductiva).

María fue, en verdad, humilde. Cuando Dios busca un socio para su propia obra redentora, su mirada siempre se posa sobre alguien que es tapeinos, humilde. La cualificación para la elección divina es la tapeinosis de aquellos que viven humillados, en su propia sociedad, porque no poseen algo que ella valora mucho. Por ejemplo, Dios escogió a un grupo de esclavos oprimidos de Egipto para fundar Israel como luz de las naciones. Incluso antes, el favor de Dios recayó sobre una pareja que no podía enfrentarse a su sociedad, debido a la vergüenza en que habian incurrido por su esterilidad. Sifi embargo, ellos fueron elegidos por Dios, no necesariamente porque eran santos, sino sólo porque eran humildes. Este parece ser el principio general de elección en la Biblia. Llegan a ser santos sólo cuando comienzan a llevar a cabo la misión para la cual fueron elegidos.

Así, en el Magnificat, esta humilde joven, muy favorecida por Dios, se alegra de que será llamada "bendita", porque Dios hizo cosas poderosas en ella, a causa de su humildad. Esta confesión de fe, que hace María, bien puede ser vista como la novena bienaventuranza:

Dichosos los humildes, pues serán escogidos para ser compañeros de Dios, en la obra de la redención.

El resto del Magnificat no es más que un comentario a esta bienaventuranza mariana. Los versos 51-53 muestran que la ira profética de Dios se desencadena contra los que no son humildes. Dios dispersa a los ostentosos, a los de la clase alta (huperephanous); destrona a los que ejercen el poder (dunastas) y manda a los ricos (ploutountas) con las manos vacías. Del otro lado (es decir, del lado de Dios), a quienes no tienen ningún status social (tapeinous), Dios los ensalza, es decir, los eleva a ser colaboradores suyos; y a los hambrientos, es decir, a los indigentes que carecen de lo esencial para la vida (peinontas), Dios los llena de abundancia de bendiciones. 
Este cambio revolucionario que Jesús trae consigo demuestra claramente el rechazo de Dios a una sociedad que los humanos dividen entre grupos de status elevado y bajo. Dios manifiesta su protesta divina, en medio de y por medio de los grupos de bajo status. La implicación de esta protesta divina parece ser que la única forma de impedir que Dios invierta la situación actual de ambos grupos es eliminando, por nuestra propia iniciativa, la diferencia de clases o de castas. Esta es una exigencia fundamental del reino de Dios.

Así, cuando Dios-en-Cristo viene a convivir en medio de nosolros los humanos, se convierte en un humilde entre los humildes, un tapeinos entre los tapeinoi. Lo mismo vemos, descrito en forma gráfica, en la "meditación de las dos banderas". San Ignacio contrasta el "lugar humilde", en el cual aparece Jesús (Ejercicios espirituales, n. 144), con la "cátedra" sobre la que se sienta el enemigo (n. 140). También san Pablo dice de modo explícilo que Jesús, en cuanto realidad divina, "tomó la forma de los humildes" o "se abajó socialmente a sí mismo" (etapeinosen eauton). En Filipenses 2, 5-11, se nos dice:

El, siendo (huparchon) de condición divina (siendo de condición divina = "porque" era de condición divina, no "aunque" era... ),

no se apegó a su igualdad con Dios, sino que se redujo a nada (ekenosen), tomando la condición de servidor, y se hizo semejante (homoiomati) a los hombres.

Y encontrándose en la condición (schemati) humana (psico-social), se rebajó a sí mismo (etapeinosen eauton), haciéndose obediente hasta la muerte, y muerte en una cruz (muerte reservada a los esclavos, el estrato más bajo de la sociedad).

Por eso, Dios le engrandeció

y le dio el Nombre que está sobre todo nombre...

"Siendo de condición divina", es decir, debido a su condición divina, se enamoró (en el original: he 'fell' in love), es decir, descendió (he 'fell') al status de esclavo al aceptar la humillante pena de muerte, reservada a la escoria (los humiliores) del imperio romano, es decir, los esclavos. De nuevo, el verbo tapein (bajar en el status social) describe su conducta divina. Descendió al abismo del abajamiento social como un esclavo, y. por ello. ascendió como Señor sobre todos.

Se puede percibir aquí la alusión que hace Pablo al contraste entre Cristo y Adán, quien hizo exactamente lo contrario: Adán trató de exaltarse a sí mismo para llegar a ser igual a Dios y cayó en el abismo del pecado.

Jesús, por lo tanto, no sólo se hizo humano entre los humanos, sino que se identificó con los grupos de bajo status social. Siendo uno de los humildes, ejercitó la mansedumbre en favor de ellos. 


\section{Una "devoción" sin “desviación": consagración, reparación y consolación}

\subsection{Lo devoción de los "mansos" como Cristo a los "humildes" de Cristo}

A la luz de nuestra reflexión bíblica sobre la verdad del corazón de Jesús, podemos revisar ahora las palabras claves que han determinado la naturaleza de la devoción tradicional al corazón de Jesús: consagración, reparación y consolación. Entre los teólogos prominentes, fue Karl Rahner quien, intentando, por una parte, proveer una base cristológica a esta devoción, ya advirtió a la Iglesia de las dudosas e incluso nocivas consecuencias de la práctica de la reparación y consolación al corazón sangrante de Cristo.

La práctica de la reparación por el daño causado al Sagrado Corazón (expresado pictóricamente como un órgano fisiológico traspasado y sangrante) y la consolación que somos llamados a ofrecer al Cristo entristecido y sufriente contradice la verdad revelada de que Cristo, la segunda persona de la Santísima Trinidad, existe ahora como resucitado de entre los muertos y reina gloriosamente con el Padre. Ese Cristo no puede hacer ni sufrir daño alguno, que necesite reparación, ni experimenta desolación alguna, que pueda ser superada al ofrecerle nuestra consolación. Tal devoción sería una desviación, una forma de inversión patológica.

Basta una cristología sensata para comprender que el corazón sangrante de Jesús, que necesita reparación y busca consolación, está en sus miembros, es decir, en los humildes, quienes forman un cuerpo con él, aquí en la tierra. El mismo Cristo nos dice dónde espera él reparación y consolación, al referirse a sí mismo como el sacramento de aquelios que, de nuestra parte, necesitan alimento, vestido y techo, nuestro cuidado e interés en la enfermedad, y nuestro alivio y consuelo en la prisión (Mt.25, 36ss).

Según esto, cuando nos consagramos al Corazón de Jesús, manso y humilde, aceptamos el "yugo suave" y la "carga ligera" de ser mansos y humildes como él. Esto quiere decir:

a) que nos unimos a la persona de Cristo (que es Jesús junto con los humildes, hechos alianza en un solo cuerpo), como el objeto de nuestro amor y servicio apasionado, en un compromiso de por vida, que renueva incesantemente nuestra vocación bautismal;

b) que consagramos, dedicamos, lodas nuestras fuerzas y capacidades con total entrega a los humildes, ejercitando la ira profética, que desenmascara y rechaza la injusticia, haciendo reparación por el daño hecho a los miembros perseguidos de su cuerpo, donde reparación implica devolución de sus derechos y reslauración de la justicia;

c) que nos asociamos a los humildes (como nos lo recomienda Pablo en Rom $12,16)$ para compartir con ellos el consuelo, que proviene del cumplimiento de la promesa que Dios les ha hecho ( $L c 1,51-53)$. 


\subsection{Consagración de la familia al Sagrado Corazón: una fórmula alternativa}

Como conclusión de estas reflexiones, quisiera ofrecer —en una especie de aplicación pastoral- una nueva fórmula de la "Consagración de la familia al Sagrado Corazón", en la cual se incorpora lo que acabamos de decir, sin perturbar la fe sencilla del cristiano. (Esta oración fue publicada por primera vez en Sri Lanka y después fue ampliamente distribuida por el padre Pio Ciampa, S.J., en África, con la aprobación del obispo S. Ndingi, de Nakuru.)

Señor Jesús, que te inflamas en amor por nosotros. Tú has revelado a Santa Margarita María que esperas ansiosamente que los hogares cristianos te inviten a su casa como a su cabeza y Señor. Accediendo a este deseo tuyo y aceptando tu amor, nos juntamos hoy como familia tuya y renovamos nuestra promesa baulismal para ser sólo lo que nos has mandado que seamos y para evitar lo que te disgusta, creyendo firmemente que tú nos buscas como pastor cuando nos descarriamos y nos acoges como amigo cuando regresamos.

Jesús, manso y humilde de corazón, huésped invisible en nuestras reuniones de familia. Tú eres el lazo de unión entre nosotros, nos llamas a perdonarnos unos a otros los males que nos hacemos y a apoyamos en nuestros trabajos.

Jesús, manso y humilde de corazón. Que seas siempre el centro de nuestra vida, el único motiv decimos, nuestro consejero en todo lo que planificamos, nuestra guía y compañero en todo lo que hacemos, la fuente de nuestro gozo cuando tenemos éxito, la fuente de nuestro ánimo cuando fracasamos, nuestro consuelo en el dolor, nuestra esperanza en las pruebas y nuestra fuerza en la tentación.

Jesús, manso y humilde de corazón. Que te reconozcamos siempre y te sirvamos en los pobres y necesitados. Que seamos siempre una fuente de alivio y consuelo para ti en los afligidos, que tengamos la valentía de verte a ti y defenderte en aquellos que son tratados injustamente. Pues es tu deseo que, a través de nuestro servicio y solidaridad, hagamos reparación por el daño que se hace a tu Sagrado Corazón en los más pequeños de nuestros hermanos y hermanas, desirozados y dispersos a causa de nuestros pecados.

Jesús, manso y humilde de corazón. Que nuestra familia sea recibida en tu reino por tus pequeños a quienes hoy servimos como a tus vicarios sobre la tierra, de modo que podamos cantar con ellos tus alabanzas, en compañía de María, tu madre y nuestra madre, y de todos los santos por siempre. Amén.

Sagrado Corazón de Jesús, en ti ponemos nuestra confianza.

Inmaculado Corazón de María, ruega por nosotros pecadores. 